\title{
Gratitude and its drivers within higher education
}

\begin{abstract}
.
This paper proposes that gratitude has a place in enabling us to understand students' experiences of higher education, and this has an implication for higher education (HE) marketing. This research examines the evidence for and focus of gratitude within the context of an undergraduate course with high levels of student satisfaction. It finds that final-year students report feelings of gratitude and that students report that those feelings of gratitude are at their height within the final year. This exploratory research proposes that feelings of gratitude are driven by four factors: helping behaviors; care; perceived effort; and environment. For HE marketers, this suggests that there is merit in placing emphasis on academic-student interactions at the heart of marketing strategies, including branding strategies, open day events, marketing communications and social media content. There are clear opportunities for academics and marketing departments to benefit from the intention to give back that is central to the notion of gratitude.
\end{abstract}

\section{Keywords:}

gratitude; higher education; student experience; relationship marketing; students; academics; reciprocity. 


\section{Introduction}

This paper argues that gratitude has a place within the experiences of undergraduate students with high levels of satisfaction. By identifying its drivers, we can better understand how to harness feelings of gratitude and, in turn, student satisfaction. This understanding is helpful to those who develop strategies to market higher education.

As UK institutions grapple with strategies to improve National Student Survey (NSS) scores and address Teaching Excellence Framework (TEF) requirements, the answer may lie in part in understanding and engaging with a concept at the heart of human interactions and relevant to all cultures (Gouldner, 1960), reciprocity and more specifically, gratitude. We know that gratitude and satisfaction are distinct concepts and can exist without each other (Raggio, Walz, Godbole \& Folse, 2014:18); however, the positive characteristics of gratitude give us reason to think that students who have feelings of gratitude might also have high levels of satisfaction. Indeed, it is possible that one expression of gratitude could be higher NSS evaluations.

So does higher education (HE) generate feelings of gratitude amongst students? Is this one explanation for strong NSS scores? Can this inform strategies for the marketing of HE? Might an understanding of the nature and drivers of gratitude enable us to sustain and build high NSS evaluations of $\mathrm{HE}$, inform our approach to TEF and enhance alumni involvement with HE? This research seeks to make an early contribution to this conversation.

This study is informed by relational perspectives to higher education, a valuable way of thinking about HE from a marketing perspective. Relational perspectives emphasize ongoing interactions between relational partners. Whilst a range of scholars have sought to bring relational ideas to the study of HE (e.g., Helgesen, 2008; Bowden, 2011; Bowden \& Wood, 
2011; Raciti, 2012; Cownie, 2014; Cownie, 2016), few have yet embraced the concept of gratitude. This is surprising given that reciprocity is arguably central to relational exchange within both consumer (Bagozzi, 1995) and business-to-business contexts (Houston \& Gassenheimer, 1987; Nevin, 1995; Rao \& Perry, 2002), and gratitude is the emotional core of reciprocity (Becker, 1986; Dewani \& Sinha, 2012).

Gouldner's (1960) seminal piece establishing reciprocity suggests that reciprocity makes two inter-related, minimal demands: people should help those who have helped them; people should not injure those who have helped them. Such demands may be the result of a sense of obligation or indebtedness in which the receiver of help perceives that their response to the help-giver is the right thing to do, the dutiful thing to do, or something that they should do. That is, the response is normative and possibly perceived negatively (Pelser, Ruyter, Wetzels, Grewal, Cox \& van Beuningen, 2015). In contrast, the demands may be positive, motivated by a desire to give back or to avoid harm to the giver; this is the focus of gratitude embodied within this study.

Reciprocal exchange has been studied within a range of business interactions including: consumer-frontline employee (Bock, Folse \& Black, 2016); consumer-retailer (Morales, 2005; Hasan, Lings, Neale \& Mortimer, 2014; Huang, 2015; Dewani, Sinha \& Mathur, 2016) manufacturer-buyer (Palmatier, Burke Jarvis, Bechkoff, \& Kardes, 2009); seller-reseller (Pelser et al., 2015); and employee-manager (Webb Beck, 2016). This study argues that education is a particularly apt context for the study of reciprocity and gratitude.

Reciprocal exchange in the form of giving and receiving is central to educational practice: giving and receiving feedback; giving and receiving information; giving opportunities for engagement and responding to those opportunities; giving in the sense of inspiring and responding positively to that sense of inspiration. It is this centrality of giving and receiving that makes gratitude so relevant to the context of HE. Gratitude has the potential to be an important 
new idea within $\mathrm{HE}$, with the capacity to challenge or complement the current focus on satisfaction. This exploratory qualitative research seeks to contribute new understanding about gratitude, aiming:

To investigate the evidence of gratitude within final-year students' experiences of higher education within a high NSS-scoring course.

\section{Literature Review}

\section{Defining gratitude}

Authors agree that gratitude is an emotional response to a perceived benefactor (e.g., Fredrickson, 2004; Raggio et al., 2014). Dewani \& Sinha (2012) emphasize the importance of a desire to act resulting from this emotional response. It is this desire to respond which arguably distinguishes gratitude from appreciation, where appreciation is recognition of value without an implicit desire to respond.

Palmatier et al.'s (2009) much cited (e.g. Dewani and Sinha, 2012; Raggio et al., 2014; Huang, 2015; Pelser et al., 2015; Cownie, 2016) quantitative work within both consumer and businessto-business contexts develops Morgan and Hunt's (1994) Key Mediating Variable framework to include gratitude. Palmatier et al. (2009) define gratitude as the emotional appreciation for benefits received, accompanied by a desire to reciprocate' (p. 1), drawing from Emmons and McCullough (2004) and Morales (2005). However, arguably their creation of two constructs 'feelings of gratitude' and 'gratitude-based reciprocal behaviors' - loses the essential distinctiveness of gratitude as a coherent concept. This paper argues that whilst Palmatier et al. (2009) define gratitude in a manner which encompasses a behavioral response, in fact their construct definition presents appreciation alongside reciprocal behaviors as two distinct 
constructs. In doing so, they lose the essential nature of feelings of gratitude: an emotional response combined with an intention to respond.

This study, whilst acknowledging the importance of Palmatier et al.'s (2009) work in defining a central place for gratitude in relationship marketing, challenges their conceptualization of appreciation and reciprocal behaviors motivated by obligation. Instead this study, drawing from Dewani \& Sinha (2012), argues that the conceptualization of gratitude within HE should be articulated to connect feeling and intentional aspects of gratitude within one construct which emphasizes desire rather than obligation to reciprocate.

This paper proposes that the construct 'feelings of gratitude', whilst centered on the emotional nature of gratitude, is critically accompanied by a reciprocal response borne of want rather than obligation. 'Feelings of gratitude' provides the conceptual lens for this analysis of gratitude within HE and can be defined as:

\section{A positive emotional response accompanied by an intention to demonstrate appreciation to the perceived giver of valued benefits.}

It is the desire to respond which makes gratitude so potentially powerful within the pedagogic context, including students' willingness to engage and provide feedback. Additionally, many marketing approaches for HE, such as open day events, provision of testimonials or positive social media content, utterly depend on students' willingness to give back to academics or the institution

\section{Gratitude and outcomes}

We know that gratitude is an important driver of relational outcomes including satisfaction (Palmatier et al., 2009; Raggio et al., 2014); indeed, Mishra (2016) found gratitude to be a more 
powerful driver of relational outcomes than either trust or commitment. Bock et al. (2016) found that the relationship between gratitude and relational outcomes was facilitated by supportive interactions between employees and customers. Interactions between employees and customers may not only influence the impact of gratitude, but also the generation of gratitude. Dewani et al. (2016) propose that social investments, including interpersonal interactions, generate gratitude. Thus, it is of value to understand how gratitude might be generated in the context of HE in which interpersonal interactions facilitate learning and engagement within the wider opportunities of HE.

\section{Drivers of gratitude}

Scholarship highlights a range of potential drivers of gratitude. Relational investments are a broad driver adopted by both Hasan et al. (2014) and Palmatier et al. (2009). Huang (2015) disaggregates relational investment into distinctive factors and finds variability in the impact of these factors on gratitude, with preferential treatment being the strongest factor driving gratitude, followed by interpersonal communication and rewards. Preferential treatment is also a strong driver of gratitude alongside core benefit provision within the context of prioritization schemes (Wetzel, Hammerschmidt \& Zablah, 2014). The importance of communication as a driver of gratitude was also highlighted in Ting and Huang's (2015) work in Taiwanese special schools. This highlights some of the challenges of considering gratitude within the educational context, as here a key driver of gratitude found in Huang's (2015) and Wetzel et al.'s (2014) studies, preferential treatment, would be of concern within an HE context due to its potential connection to ideas of favoritism.

Intentionality and benevolence are important aspects of gratitude (Ceaser, 2012). Hasan et al. (2014) find that perceived benevolence has a moderating effect between relational investments and gratitude. Perceived effort is a driver of gratitude (Morales, 2005); indeed, gratitude can be experienced resulting from effort rather than outcome, and win-win 
situations can generate gratitude (Raggio et al., 2014). This suggests that aspects of the learning process associated with investment of effort may be generators of gratitude, rather than outcomes such as assessment grades.

\section{Gratitude and education}

Little research has been conducted on gratitude within higher education: Fournier and Sheehan (2015) examined gratitude among undergraduate nursing students in the US, recommending that gratitude be integrated within students' learning. Yuksel and Oguz Duran (2012) adapted McCullough, Emmons, \& Tsang's (2002) gratitude questionnaire for Turkish undergraduate students, concluding that it may have a contribution to identifying students' counseling needs.

In contrast to these very specific studies, Howells' (2012) work on gratitude within the Australian secondary education context is a valuable underpinning to a study of gratitude in education. Howells' (2004) early exploration of gratitude in education examined gratitude's place within the HE context, and most recently, her collaborative study (Howells, Stafford, Guijt \& Breadmore, 2017) examines gratitude's place within doctoral supervisory relationships. Howells et al. (2017) find that gratitude practices conferred focus and intentionality within these supervisory relationships with improved research outcomes and attrition. However, recent work by Cownie (2016), in the context of media practice education, finds that whilst students speak positively about gratitude's place within their student experience, there is variation in academics' interpretation of gratitude, several voices seeing gratitude negatively, inter-changing gratitude with obligation.

In summary, this study, in seeking to analyze gratitude within the context of relational exchange in $\mathrm{HE}$, draws from recent and well-cited scholarship within the realm of relationship marketing within consumer and business-to-business contexts (e.g., Palmatier et al., 2009; Raggio et al., 
2014). As a new area of research, there is little extant scholarship about gratitude within the context of HE, but the work of Howells (2012; 2004) and Howells et al. (2017), set in the educational context, provide a complementary set of ideas to those presented within the Relationship Marketing scholarship. This study seeks to add to the body of knowledge of gratitude within education, in its exploration of experiences of gratitude amongst students within higher education.

\section{Methodology}

This exploratory study examines two research objectives:

- To explore the evidence and focus of gratitude within final-year undergraduate students' experiences of a high NSS-scoring course;

- To explore the drivers of gratitude within final-year undergraduate students' experiences of a high NSS-scoring course.

Students were recruited from a high-performing undergraduate marketing course within one higher education institution (HEI). The four-year sandwich course had a consistent pattern of high overall satisfaction as measured by the NSS over the previous three years: $95 \% 2015$; $97 \% 2014 ; 92 \% 2013$. The course was ranked as the third-best performing course across the university within which it was located. Its cohort size at 66 (2015) was significantly larger than the cohort size of the first and second ranked courses within the university. The cohort under study were the first group of students to have paid $£ 9,000$ tuition fees.

The fact that the sample is drawn from a high-performing course arguably makes this an outlier case study; however, the opportunity here is to explore the potential role of gratitude within an educational context which has been judged by students to be of a high standard. The focus of inquiry is, does gratitude have a role to play within positive, functional HE contexts? 
Final-year students on the selected course were invited to participate in the research. Clearly, those who responded may not be representative of the whole cohort; perhaps their willingness to engage in research indicated higher levels of engagement. However, given the nature of this study, in trying to understand the experiences of satisfied students, this is perhaps less problematic than had it intended to understand gratitude across the entire student population. The diversity of response from the students involved generated confidence that a variety of perspectives were captured.

\section{[insert table 1 here]}

The sample comprised 15 final-year undergraduate students (see table 1), 11 of whom were female; 4 were male. All were aged between 18-24. The majority of the sample were UK students, with 2 from overseas, including the EU (reflecting the balance of students on the course).

Participants were interviewed individually using a semi-structured research tool which sought to prompt participants' experiences of being a final-year student, and within this, to consider issues of engagement and gratitude. Gratitude was introduced mid-way during the interview with participants being asked to talk about a recent experience of being grateful. This allowed the researcher to assess whether gratitude was being conceived as an idea which reflected the characteristics of gratitude (positive; intention to respond) articulated within its definition for this study. If not, then the proposed definition was shared.

Interviews were around one hour in duration (see table 1), generating 16 hours of data over the period February-March, so during the period in which NSS data is collected. This is clearly a relatively small sample but is within guidance offered by Guest, Bunce \& Johnson (2006) that data saturation can be as early as within six interviews but frequently within twelve. All 
interviews were transcribed and transcriptions were analyzed inductively with Nvivo 11, using emerging themes to develop the conceptual ideas and constructs which found a place within the proposed conceptual framework. One of the limitations of the study was that it was conducted by a single researcher, which may have an impact on the reliability of the coding. The student interviews did, however, follow a series of interviews with academics on gratitude, within which stable coding was developed.

In summary, this exploratory research sought to generate an understanding of final-year undergraduate students' experiences of gratitude in HE. To do this, the research planned to examine the evidence and focus of gratitude and possible drivers of gratitude. This would facilitate the development of a conceptual framework seeking to explain gratitude's place in the context of final-year students' experiences within a functional educational context. The emerging framework could be examined quantitatively in future studies in order to generate empirical evidence to test the hypotheses it represents.

\section{Discussion}

\section{Research objective 1}

- To explore the evidence and focus of gratitude within final-year undergraduate students' experiences of a high NSS-scoring course.

The notion of gratitude resonated with research participants, all of whom were able to relate to gratitude (conceived as appreciation combined with a desire to reciprocate) within their finalyear student experience. In particular, students spoke about being willing, indeed wanting to engage within the learning context, whether that be participating in seminar discussions or investing effort into assessments. This appeared to be a response to an increasing appreciation of the benefits of their educational experience. Indeed, one of the key themes which emerged 
was change over the duration of the course. Students spoke about the distinctiveness of the final-year experience. One student reflected upon her experience of the final year, highlighting the energy and effort she was willingly prepared to put into her studies and indicating a reciprocal dynamic:

\begin{abstract}
Obviously we know we're at the stage where we know this is what we want to do, this is like the course we've chosen, and we're really enjoying it, and it's what we want to do in the future, like it's helping us start our careers, so I think it's, we're at that point where we should maybe take it really seriously, I think for me personally I'm more willing to participate and like ask a lot more questions, and I'm maybe not so scared to sort of email people and ask questions. And I think it's because you feel like you want to do well, and this is kind of your last chance to do well, you want to put all of the extra effort in, so you want to do all the readings, and you're gonna participate in all of the classes and go to all of the lectures, and I think that's how you kind of give back to the lecturers.
\end{abstract}

Participant K: female.

The year-placement was identified as contributing to students' approach towards their finalyear. However, the distinctiveness of the final year was in the main linked to the investment of time and effort students were putting into their studies and the relationships forged with tutors and other students which felt more equal and collaborative than in previous years.

[Gratitude] I think it's a lot more applicable in final year as well, though because I think as a student you invest a lot more time in it, well myself I did, because I know it's the most important, and it becomes I think, you know when everyone says after placementyear you become more focused, it genuinely was true for myself, because I found myself actually really wanting to get more engaged, and wanting to put more into it. And I think when you get a lecturer that you can genuinely see goes out of their way, I 
respond to that... when it's more on a personal level and you can really see that people care, I think that really resonates.

Participant G: female.

The foci of the gratitude within the students' final year were academics, students within their cohort, student mentors and the institution. Students spoke about relationships with peers having a collaborative nature, whereas in previous years, more competitive relationships existed between students on the course. One student talked about the combination of gratitude towards academics and students that he experiences, noting how gratitude between students enhances the overall experience of being a final year student.

l'd probably say it can fluctuate in terms of where you are in the process and there's probably individual spikes where it's played a big role. Things like when [tutor] helped me funnel down my dissertation, that was really, that was a big deal for me in that area because I was incredibly worried.... but then at the same time there's smaller parts, little day-to-day things that make it just a more pleasurable experience. That's probably like a peer thing, so student-to-student, little bits and bobs that help each other get by and sort of "we're all in it together" sort of thing. It's the smaller things that won't necessarily get picked up on, but without them you would notice and there would be a much more glum experience. So yes, there's definitely spikes, and that's probably when it's with tutors. And then there's sort of like a hum of gratitude going along with students.

Participant A: male.

However, for some students, the final year comprised as much variation in experiences across different units as had previous years. Tutors' interactions with students appeared to be at the heart of this variation. One student commented: 
I suppose when they like, I know this sounds bad, but I feel like when tutors like actively want to help you, that sometimes can be a bit rare. Like sometimes you go into a unit and then they're a bit like "you're only allowed this amount of time, this amount of help, and we can't give you any more help", and then when you go and see them they can be, l've found sometimes like if, some tutors that I've seen, I go to their office and they're really like blunt and like just don't make you feel very welcome. And you feel like, I don't know, whereas I feel like the tutors that are really like open and "oh come in" and have a chat with you, and they're really, you feel much more grateful for that kind of happening, I always find there's like a mix every year. So you'll have some tutors who are like up there, like really helpful, and then you have some who are really like don't even want to know your name. They're a bit cold.

Participant J: female.

Whilst many students spoke about gratitude in the context of people (academics/students), there was evidence that for some students, the institution was a focus of gratitude. This student reflected on all the university had done to help her and how this generated feelings of gratitude towards the university which she considers will be sustained over time:

I think gratitude has definitely like added to my university experience. More so in final year. But I think when I leave I will always feel grateful for what [university] has like done, whether it be placement, you know, help in final year, because it's such a tough year. I know so many people from other universities that didn't get that time, you know, with their tutors and they really struggled. So I would always feel grateful for [university] and like what they've done. Because I don't think I ever would have got like a [company] placement without that, and obviously that's going to hopefully be a massive help when I leave [university]. So it's always that element of feeling grateful.

Participant N: female. 
Therefore, the data suggests that these final-year students, studying on a well ranked (in terms of student satisfaction) undergraduate course, do feel grateful for aspects of their HE experience and that gratitude is directed towards academics, fellow students, student mentors and the institution. It is possible that gratitude and satisfaction co-exist independently (Raggio et al., 2014) or that satisfaction is an outcome of gratitude. This could be explicitly examined in future research.

\section{Research objective 2}

- To explore the drivers of gratitude within final-year undergraduate students' experiences of a high NSS-scoring course.

We see from the literature that outside the context of $\mathrm{HE}$, relational benefits and effort are drivers of gratitude (Morales, 2005; Palmatier et al., 2009; Raggio et al., 2014; Hasan et al., 2014). Themes emerging from the data appeared to suggest that these ideas may have relevance in HE. Four themes were identified, each providing evidence of a potential driver of students' feelings of gratitude.

\section{Helping behaviors.}

Helping behaviors were cited by all participants as an important aspect of the student experience which generated feelings of gratitude. These helping behaviors were provided by both academics and other students. This reflects Bock et al.'s (2016) findings in commercial

environments, in which supportive employee-customer interactions generate feelings of gratitude which in turn drive positive relational behaviors. 
Students recalled in some detail the help received during past years, in particular by academics, but also by student mentors. Guidance provided within the learning environment was certainly recognized as helpful, including weekly tasks, the provision of real-life examples and the underpinning of a detailed unit guide. Students felt that helping behaviors were more

evident in the final year than in previous years of their degree. However, variation in helping behaviors across units within the final year was noted by many participants. It appeared that such variation was associated with students' perceptions of the depth of relationship between student and academics. In the units which were characterized by helping behaviors, one student spoke about engaging reciprocally; however, she felt that in other units, academics were not providing the help that she expected:

Yes, I feel like the lecturers who give more of their time and they like, they're more open. So, if you like need some help with something, "OK, come to my office or whatever, we'll chat through", or like they make one to one meetings with you. Then it's, I find that I engage more in the unit, because I feel like you're getting a bit more of feedback and a bit more help. But some of the units where it's like "OK, well you can have like, you're only allowed, you're not allowed to email me, I won't respond to your emails because it's above and beyond my role. If everyone emails me then I can't reply to everyone, it's not fair, blah blah." And then they're a bit like, if you have a meeting with them, they time it to the T, you feel a bit like, I don't know, you just feel like a bit on your own, like they're not helping you as much as they should.

Participant J: female.

There was little mention of the institution demonstrating helping behaviors: perhaps helping behaviors are intuitively linked with people rather than institutions. The one exception of the institution being the origin of helping behaviors was related to the placement. Even then, a mention of specific members of the placement support team was evident: 
I think searching for a placement was a huge thing...I felt gratitude towards like [placement support administrator], for example, for all the help she gave me. But then also to the university as a whole, because they've set up this network where students can go to or turn to if they are stuck for plans for placements.

Participant M: male.

Interestingly, 'small things' were frequently mentioned in association with helping behaviors: small things were seen to be meaningful and arguably have a surprisingly important impact on gratitude.

I think it's if someone does something for you, it might not even be big, like one person might be something massive, the other person might be something small, but you want to, especially for me anyway, if someone does something for me, you want to do it back.

Participant C: male.

Importantly, students spoke about helping behaviors supporting rather than undermining independent learning. Students felt that initial help gave them the confidence to move ahead as independent learners. Students commented about the importance of help at the early stage of planning their work:

I think it's like when you're starting out with an assignment or something, you want more help so that you know that you're going in the right direction, and then once you've got that initial help, you kind of, then you become the independent learner because you can go off and do it. But it's that kind of initial assurance that you're like going along the right tracks, and you're not going off on a completely different tangent kind of thing. 
The reciprocal nature of the student-academic relationship means that there is an explicit attempt to not let a helpful lecturer down. This reflects Gouldner's (1960) ideas that people avoid harming those who have helped them. Students' achievement is for themselves, but also for academics who they perceive have exhibited helping behaviors.

I think the more help and guidance a lecturer gives you, the more I feel a sense of, I need to work hard, umm, and yeah, it's for me, but also for them as well, because you can't let them down, and I think that's probably the key issue, you don't want to let the lecturer down.

Participant A: male.

One student spoke about similar feelings in the context of her relationships with her peers. Again, helping behaviors emerge as an important driver of gratitude and include reading essays, prompting peers to do specified reading, helping peers select a dissertation topic and revising.

Therefore, helping behaviors are considered as a valued benefit which generate positive feelings accompanied by an intention to respond in some manner (working harder, saying positive things about a person or situation, volunteering). Thus, helping behaviors are identified as a driver of feelings of gratitude and can be defined as:

Actions perceived to be supportive, guiding and constructive in enhancing students' HE experience and achievement. Such actions may small or large but are perceived to be important aspects of the student experience.

\section{Care}


A sense of care emerged as a key theme related to gratitude reflecting the benevolent focus of gratitude identified by scholars (Ceaser, 2012; Hasan et al., 2014). In the main, students talked about care from tutors rather than the institution. Indeed, students report that academics' sense of care for the student body and individual students appears to be easily recognized by students and a powerful aspect of the learning experience. One student commented:

It's important I think that the lecturer and the uni care about you as an individual rather than kind of caring about your results, or just that you're here.

Participant A: male.

Students spoke about care in several ways: care for the unit; care for students as individuals; care that students succeed. Interestingly, the conversations with participants focused on care within the context of the learning experience rather than pastoral care. There was a clear sense that care characterizes a functional relationship between academics and students. Participant A continued to comment about the care he observes academics show about their unit and how that sense of care enhances his learning:

If I know that the tutor feels like they really care about the unit, and you can see that when they're teaching it, and that they really know about it and that they're very attached to the unit and sort of they believe everything they're saying, they're not sort of saying "right, this is what so and so said, this is how I relate it", they really believe what they're telling you, that really makes you want to engage in the unit, and it makes you sort of, it makes you much more confident in your own viewpoint.

Participant A: male. 
Students appeared to perceive variation in the extent to which academics cared about their students, although one student commented that whilst she could see this, she wasn't quite sure how she evaluated care:

Yes, I'd say I definitely perceive some lecturers and tutors as caring more than others, but I don't really know how I make those judgements.

Participant K: female.

Another student felt that communication was key to care:

I feel like if a lecturer shows they care, they'll go out of their way to do things for you. Not necessarily just take the seminar or lecture, it's just little things like "Oh, how are you doing? How are you getting on?" or "How was your weekend?" or, you know, or just emails that say "Thank you for coming" or whatever. It shows that they not only care about their like module or whatever, they care about you as a person. Whereas other lecturers will, they just won't do that.

Participant I: female.

Therefore, it is proposed that care is a driver of feelings of gratitude. The benevolence of care is valued by students and generates positive feelings accompanied by a desire to reciprocate. Care is defined as:

The explicit attention and interest demonstrated by academics within the context of the learning experience: this is directed towards specific students, the student cohort and their success, and the delivery of the unit.

Care is about interest and attention in people and the focus of learning, whereas helping behaviors are actions which may be driven by care, but could also be driven by other factors such as professionalism or pedagogic philosophy. 


\section{Perceived effort}

Students spoke about the perceived effort they observed within academics and other studentfacing staff as being a factor which generated feelings of gratitude. The effort academics expended by being enthusiastic and making sessions interesting was considered a driver of gratitude. Students repeatedly spoke about academics who 'go the extra mile' or 'go over and beyond' as being recognized for their efforts and the subsequent focus of feelings of gratitude. Perceived effort was an indicator of academics' investment into students and, in turn, generated a desire to reciprocate. This reflects the findings of Morales (2005) and Raggio et al. (2014) in which effort, not necessarily accompanied by outcome, is valued and generates feelings of gratitude.

Yes, so if you think that one person has put in a lot of effort and helped you a lot to do well, you don't want to then let them down by not doing as well later on, because obviously they care about you doing well, if they're willing to help you to put in that bit of extra effort, or if you feel like they're kind of invested in what you're doing.

Participant K: female.

One student spoke candidly about her lack of engagement but how she could be stimulated to reciprocate by the perceived effort of her tutors. She explicitly linked perceived effort with feelings of gratitude and reciprocal exchange:

So I think that the sort of gratitude I felt from her putting all of that effort in and sort of like... I guess just the way she's gone about it, I've become grateful, I was grateful, and obviously I could sort of be like one, not like a step ahead, but I could sort of like be like on top of everything, and so obviously I hope that my gratitude for that was 
shown by having had, done my work and obviously just sort of being to a point where we were like engaging each other sort of like with my project, rather than just asking silly questions.

Participant L: female.

Tutorial support was specifically mentioned as an indicator of perceived effort from academics. Students seemed to recognize the time intensiveness of this form of teaching and therefore the effort that tutorials involve. Another re-occurring theme was the effort academics made or did not make to learn students' names, for example:

Yes, and they're making an effort to like know your name, and like, I noticed with [tutor's name], [tutor] knew everyone's name like within the first kind of couple of lectures, and [tutor] made an effort at the beginning to like write your name and everything so [tutor] gets to know us, whereas some lecturers I'm pretty sure they wouldn't even know my name now, and l've had like meetings with them and they wouldn't know who you are, yes.

Participant J: female.

It was interesting to hear how early within a unit's delivery, judgements about perceived effort could be made. The quality and extent of the unit guide was mentioned as an indicator of perceived effort by one student: she had evaluated the unit guides well before her return to University for her final year, and on this basis had selected reading to take on holiday with her. She also spoke about students' evaluations of the effort the tutor had made right from the outset of the delivery of the unit, and how this would have an impact on their intended reciprocal behaviors:

We would all talk after our lectures and it would be "oh, do you think she's good? Like, is it gonna be a good unit?" and that kind of thing, and the general consensus 
on the [tutor] was "OK, yes, we're gonna contribute. I really like her, she's engaging." And so we were all like "Yes, OK, so we'll do the work". So yes, I'd say you definitely get a sense of how much they're gonna give from the first lecture in the sense of they're there on email, they really want us to do well, you can tell that they're passionate about their subject, and they don't speak too fast so that it's all too confusing and overwhelming.

Participant H: female.

One student related her expectations of effort with the money she is paying for her education, and suggested that going above these expectations generates feelings of gratitude.

Because we're paying for this, and because l'm paying to be here, there is a sense obviously that I expect a level of effort from a lecturer, for example. And that kind of comes back into play where I was talking about, so therefore if you have a lecturer or a unit that goes above and beyond that, that's when you start to feel gratitude, because otherwise you'd just feel entitled to what they've given you because you're paying so much money.

Participant G: female.

Entitlement, whilst not the focus of this paper, is clearly worthy of further exploration alongside feelings of gratitude in future examinations of students' experiences within HE. Such study can usefully draw from the work of Wetzel et al. (2014) who found that entitlement and gratitude were competing forces outside the context of education, within the context of prioritization schemes. Entitlement increased service cost and gratitude enhanced sales growth; entitlement reduced profit growth and gratitude increased profit growth. An initial application to HE might suggest that gratitude and entitlement might counteract each other's development, or that both can co-exist within the student body, impacting a range of outcomes which might include satisfaction. 
Perceived effort has the potential to generate a positive emotional response amongst students accompanied by an intention to do something to demonstrate an appreciation of that effort. Perceived effort is therefore identified as a possible driver of feelings of gratitude and is defined as:

Students' perceptions of the energy, communication and time academics invest in facilitating an excellent learning experience and environment.

Clearly there is potential overlap between perceived effort and helping behaviors, which could be investigated quantitatively through factor analysis. Nevertheless, at this point perceived effort appears to be directed proactively towards the cohort, whereas helping behaviors may be more reactive and often directed towards individual students.

\section{Environment}

Intangible aspects of the learning environment characterized by positivity, interactivity, approachability and a sense that students' contributions are acknowledged, respected and valued, emerged as an important aspect of the final driver: environment. One student talked about the importance of a comfortable environment within the classroom:

Like if you [tutor] want someone to give to you like in class or in seminars or lectures, it needs to be an environment where people feel comfortable basically. And then I would feel comfortable to give back. But I think people are very different when it comes to that kind of stuff, when it comes to the whole environment and feeling safe, feeling like, you know, yes, just feeling safe to contribute and to give back.

Participant E: female. 
The more tangible aspects of the environment generated a diverse range of opinion. One student talked broadly about her environment and the increasing ease and confidence she feels negotiating the spaces outside the classroom as she moves through the final year of her study.

The final year of the program was being delivered within a campus during a period in which a substantial new building was being constructed. The construction had a detrimental impact on the built environment in which the students within this sample were studying. For some students, the constructions they observed were an indicator of the growth of the university, and this was positive in that those students saw themselves attached to (as students or alumni) a growing, and therefore successful, institution. Other voices were arguably more focused on the short term, and saw new buildings as representing profligate use of their fees. Compare the voices of participants $\mathrm{O}$ and $\mathrm{B}$.

I mean I know that like that new building is going up, and I'm not even here when that's made, and that's made with my money.

Participant O: female.

It's nice to see that the uni is investing for the future, and that the uni is doing well, it's like, I don't think anyone wants to be at a uni where everything's kind of there, and nothing ever progresses, it's nice to see a uni that is building and growing and in years to come people will look back and say yeah I went to [HEI], they didn't have all those buildings, but I was there.

Participant B: male. 
One student could see how the existing built environment could be adapted in a manner which would be valued by final-year students because of the way it would facilitate even more effective learning and in turn build feelings of gratitude:

I think if they gave us, the [final years], a place to focus on work, it would subconsciously make students more grateful, because they will see it like they respect that, we've come this far, and we're [final years], and they want to make sure that we do the best we can, and secluded from everyone, being in an environment with each other.

Participant D: female.

Thus, environment is proposed to be a driver of feelings of gratitude as it generates a positive emotional response alongside a desire to engage in learning. The built environment could be aligned to the structural investments used by sellers within the commercial context, which Dewani et al. (2016) found to be generators of gratitude amongst customers. Currently this driver embraces both the intangible learning environment and the built environment, but future quantitative research could usefully examine whether these are different factors. If so, it would be important to examine whether the intangible learning environment is distinctive from other proposed drivers of gratitude and whether both (intangible learning environment and built environment) have a relationship with feelings of gratitude. At this stage, environment is defined as:

The physical and intangible environment within which students learn.

Thus, the four drivers of gratitude which emerge from this analysis in part reflect the work of scholars (Morales, 2005; Raggio et al., 2014) but also emphasize new factors, helping behaviors and environment. Perceived effort (Morales, 2005; Raggio et al., 2014) emerged as 
a distinct driver within this study. Interpersonal communication (Huang, 2015), intentionality and benevolence (Ceaser, 2012 were not defined as distinct factors, but clearly played a role within care. Neither preferential treatment nor rewards (Huang, 2015) emerged as relevant in the context of these final-year students' experiences of HE, and may be problematic for principals of fair treatment and assessment.

\section{Conceptual Framework}

To summarize, four factors are identified as potential drivers of feelings of gratitude. Figure 1 identifies the connections between these factors and feelings of gratitude which emerged from the discussions. It is clear how interactions with academics are critical to the facilitation of these factors in a manner which drives gratitude. Therefore, this exploratory research highlights the particular role of student-academic relationships and interactions in the development of gratitude within this high NSS-scoring program. It is clear how important academics are in the process of generating gratitude amongst students.

\section{[insert figure 1 here]}

The relationships between gratitude and its drivers are encapsulated within the proposed conceptual framework which emerges from this study (figure 2). This framework can be usefully tested in a quantitative manner, first using factor analysis to determine whether the four drivers are distinct factors, and second using multiple regression to provide evidence, significance and strength of the relationships within the framework. The framework could then be extended to examine feelings of gratitude as a mediator between drivers and satisfaction (figure 3: Rival framework (a)). This could then be tested against the framework proposed here and a further rival framework in which the four drivers have a direct relationship with satisfaction (figure 4: Rival framework (b)). Structural equation modelling could be used to examine the explanatory powers of the three alternative frameworks. 


\section{Limitations}

This was an exploratory small-scale study which focused on a single course in one HEl. The intent was to discover whether gratitude had a place within a program with high levels of student satisfaction, and if so, what might be the drivers of that gratitude. The participants responded to a request for participation within the research and therefore arguably represent those students who are particularly engaged. Indeed, the researcher had taught these participants in the semester before the research was conducted. This may have impacted the students' responses, although clear attempts were made to signal to participants that their honest opinions were sought. The course was selected because of its consistently high satisfaction scores (via the NSS). Whilst at the time of the research, it was not known whether these high scores would be maintained within the cohort from which participants were drawn, in fact the 2016 NSS score continued to be above $90 \%$ overall satisfaction.

Future research comprising the quantitative testing of the proposed framework would benefit from a broader research population comprising undergraduate and postgraduate students across a range of courses and HEls.

These early conversations with students show that gratitude appears to resonate with students studying on a course with high levels of student satisfaction as measured by the NSS. There is an opportunity to test the gratitude frameworks developed here and to examine outcomes of feelings of gratitude. This research suggests that there is indeed an opportunity to integrate gratitude within a broader relational framework for higher education. Given the evidence presented here of gratitude within final-year students' experiences, a natural extension of this work is to examine the evidence of gratitude amongst alumni. Such a study would examine 
implications including the ways in which alumni may be willing to, even want to, give back to the academics with whom they studied, or the institution to which they are connected.

\section{Implications for practice}

Implications for practice highlight the importance of student-academic relationships within HE and emphasize the importance of emotional labor required from academics. Marketing strategies, whether they be around open days, prospectus communication or even branding strategies, would do well to integrate and emphasize the importance of the studentacademic relationship. Equally, the four drivers proposed here should find a place within the marketing communication targeted at prospective students. Marketing directors should articulate support for university strategies which further strengthen interactions between students and academics, and should be aware of any dilution to such interactions increased student numbers might bring. Where gratitude is being generated, then the reciprocal behaviors which it precipitates can be used effectively in provision of authentic student support at open days, testimonials, engagement within social media conversations related to university experiences, participation within student ambassador programs and other activities which ultimately benefit the student experience and the reputation and impact of the university.

Outside HE, the drivers may also resonate within business contexts within which people play a particularly important role, such as consumer-frontline employee interactions (Bock et al., 2016) and employee-manager interactions (Webb Beck, 2016). In these contexts, frontline employees and managers should ensure that perceived effort, helping behaviors and care are demonstrated towards consumers and employees respectively.

\section{Summary}


This research asked whether gratitude has a role to play within functional and positive HE contexts. To summarize, this early research suggests that gratitude appears to be resonant within the experiences of students studying on a course with high satisfaction as evaluated by the NSS. It finds that final-year students do report feelings of gratitude and that students report that those feelings of gratitude are at their height within the final year. It is clear how important academics are as foci for students' gratitude and in facilitating the factors which appear at this stage of the research, to drive gratitude. The research argues that helping behaviors, perceived effort, care and environment, together generate feelings of gratitude amongst these final-year undergraduate students.

The paper proposes that investments within these aspects of the HE experience will be productive in enhancing students' gratitude. It argues that as academics are the focus of gratitude, their approach to facilitating students' learning should encompass the four drivers. The implication is that the role of the academic in the current HE context is one which has higher demands of emotional labor than previous years would have required. Indeed, it is possible that this is one of the important implications of the introduction of higher levels of tuition fees.

For marketers, these findings help us to understand the importance of academic-student interactions within students' experiences of a course with high levels of satisfaction. It reminds marketers to place such academic-student interactions at the heart of marketing strategies, including branding strategies, open day events, marketing communications and social media content. In turn, it is evident that there are clear opportunities for academics and perhaps also marketing departments to benefit from the intention to give back that is central to the notion of gratitude. 


\section{References.}

Bagozzi, R. (1995). Reflections on relationship marketing in consumer markets. Journal of the Academy of Marketing Science, 23(Fall), 272-77.

Becker, L. C. (1986). Reciprocity. New York, NY: Routledge and Kogan Paul.

Bock, D.E., Folse, J.A.G., Black, W.C. (2016). When frontline employee behavior backfires:

Distinguishing between customer gratitude and indebtedness and their impact on relational behaviors. Journal of Service Research, 19(3), 322-336.

Bowden, J. (2011). Engaging the student as a customer: A relationship marketing approach. Marketing Education Review. 21(3), 211-228.

Bowden, J. \&and Wood, L. (2011). Sex doesn't matter: The role of gender in the formation of student-university relationships. Journal of Marketing for Higher Education, 21(2), 133-156.

Ceaser J. (2012). No thanks to gratitude, Policy Review, Dec 2011 \& Jan 2012, 59-73.

Cownie F. (2016). Gratitude: Does it have a place in media practice education? Journal of Media Practice, 17(2-3),168-185.

Cownie, F. (2014). Students' reports of normative commitment within UK higher education. Proceedings of the Academy of Marketing, 8-10 July 2014, Bournemouth University.

Dewani, P. P. Sinha, P. K., \& Mathur, S. (2016). Role of gratitude and obligation in long term customer relationships. Journal of Retailing and Consumer Services. 31, 143-156.

Dewani, P. P., \& Sinha, P. K. (2012). Gratitude: An emotional approach in business relationship research. Journal of Business Management, 6(1), 1-11.

Emmons, R., A., \& McCullough, M., E. (2004). The psychology of gratitude. New York, NY: Oxford University Press.

Fournier, A. and Sheehan, C. (2015). Growing gratitude in undergraduate nursing students: Applying findings from social and psychological domains to nursing education. Nurse Education Today. 35, 1139-1141. 
Fredrickson B. (2004). Gratitude like other positive emotions, broadens and builds. In R. Emmons and M. McCullough (Eds.), The psychology of gratitude, pp. 145-166. New York: Oxford University Press.

Gouldner, A. (1960). The norm of reciprocity: A preliminary statement. American Sociological Review, 25(2), 161-178.

Guest, G., Bunce, A., \& Johnson, L. (2006). How many interviews are enough? An experiment with data saturation and variability. Field Methods, 18(1), 59-82.

Hasan, S., F., Lings, I., Neale, L., \& Mortimer, G. (2014). The role of customer gratitude in making relationship marketing investment successful. Journal of Retailing and Consumer Services, 21(2014), 788-796

Helgesen, O. (2008). Marketing for higher education: A relationship marketing approach. Journal of Marketing for Higher Education. 18(1), 50-78.

Houston, F., and Gassenheimer, J. (1987). Marketing and exchange Journal of Marketing, 51(October), 3-18.

Howells, K. (2012). Gratitude in education: A radical view. Rotterdam: Sense Publishers. Howells, K. (2004). The role of gratitude in higher education. Transforming Knowledge into Wisdom, Proceedings of the $27^{\text {th }}$ HERDSA Annual Conference, MIRI, Sarawak. July 2004. Howells, K., Stafford, K., Guijt R., \& Breadmore, M. (2017). The role of gratitude in enhancing the relationship between doctoral research students and their supervisors. Teaching in Higher Education, 22(3),1-18

Huang, M. (2015). The influence of relationship marketing investments on customer gratitude in retailing. Journal of Business Research, 68(6), 1318-1323.

McCullough, M., Emmons, R., \& Tsang, J. (2002). The grateful disposition: A conceptual and empirical topography. Journal of Personality and Social Psychology, 82, 112-127. Mishra, A., A. (2016). The role of customer gratitude in relationship marketing: moderation and model validation. Journal of Strategic Marketing, 24(6), 529-549. 
Morales, A.C. (2005). Giving firms an E for effort: Consumer responses to high-effort firms. Journal of Consumer Research, 31, 806-812.

Morgan, R., \& Hunt, S. (1994). The commitment-trust theory of relationship marketing. Journal of Marketing, 58(3), 20-38.

Nevin J. R. (1995). Relationship marketing and distribution channels: exploring fundamental issues. Journal of the Academy of Marketing Science, 23(fall), 327-34.

Palmatier, R., Burke Jarvis, C., Bechkoff, J., \& Kardes, F. (2009). The role of customer gratitude in relationship marketing. Journal of Marketing, 73 (Sept), 1-18.

Pelser, J., Ruyter, K., Wetzels, M., Grewal, D., Cox., D., \& van Beuningen, J. (2015). B2B channel partner programs: Disentangling indebtedness from gratitude. Journal of Retailing 91(4), 660-978.

Raciti, M. (2012). Predicting first year student transfer intentions: Do relationships matter? Australasian Marketing Journal, 20(1), 65-72.

Raggio, R., D., Walz, A., M. Godbole, M., B., and Folse, J., A., G. (2014). Gratitude in relationship marketing: Theoretical development and directions for future research. European Journal of Marketing, 48(1/2), 2-24.

Rao S., \& Perry, C. (2002). Thinking about relationship marketing: Where are we now? Journal of Business and Industrial Marketing, 17(December), 598-614.

Ting, S., \& Huang, T. (2015). The role of gratitude in relationship marketing: An example of special education schools. Chinese Journal of Guidance and Counseling, 43(August), 3560.

Webb Beck, C. (2016). Perceptions of thanks in the workplace: use, effectiveness and dark sides of managerial gratitude. Corporate Communications: An International Journal, 21(3), 333-351.

Wetzel, H., Hammerschmidt, M., and Zablah, A. (2014). Gratitude versus entitlement: A dual process model of the profitability implications of customer prioritization. Journal of Marketing, 78 (March), 1-19. 
Yuksel, A., \& Oguz Duran, N. (2012). Turkish adaptation of the gratitude questionnaire. Eurasian Journal of Educational Research, 46, 199-216. 